\title{
НЕМАТЕРИАЛЬНЫЙ КАПИТАЛ КАК ОСНОВА ПРЕОБРАЗОВАНИЯ РЕГИОНА
}

\author{
(c) 2021 Фахрутдинова Елена Валерьевна \\ доктор экономических наук, профессор \\ Казанский (Приволжский) федеральный университет, Россия, Казань \\ E-mail: efahr@mail.ru \\ (c) 2021 Грудина Светлана Игоревна \\ кандидат экономических наук, доцент \\ Казанский (Приволжский) федеральный университет, Россия, Казань \\ E-mail: switki@yandex.ru
}

\begin{abstract}
Статья посвящена теоретическим аспектам исследования нематериального капитала как потенциальной основе преобразования региональных социально-экономических систем. Актуальность статьи обусловлена возросшей необходимостью исследования кризиса управления социально-экономическими процессами, в центре которых - хозяйствующий субъект, «человек экономический» проявляется в новой цифровой среде, требующей углубленного исследования свойств «новой реальности», дополненной цифровыми, интернет ресурсами. Наращивание агрессивности внешней среды хозяйствования обострилось пандемией Ковид-19, поиски эффективных инструментов борьбы с которой является первоочередной задачей для большинства стран на современном этапе [6]. Исследование вносит вклад в разработку теории нематериального капитала, как фактора преобразования социально-экономической системы, нахождения стратегии резонансного преодоления кризиса управления.

Авторами уточнена и дополнена трактовка нематериального капитала как ресурса преобразования системы, что позволяет более точно прогнозировать сценарии устойчивого развития региона. Внедрение сформулированных авторами предложений по воспроизводству нематериального капитала позволит нивелировать негативные последствия кризиса управления, снизить издержки энтропии, что определяет актуальность, теоретико-методологическую и практическую значимость исследования. Объектом исследования является совокупный нематериальный капитал региональной социально-экономической системы, потенциально способствующий ее эволюции. Предметом исследования выступают социально-экономические отношения, возникающие в процессе производства, использования и конвертации капитала в различных стадиях жизненного цикла.
\end{abstract}

Ключевые слова: нематериальный капитал, система управления, кризис системы управления, информация, регион, социально-экономическая система, устойчивое развитие, резонансное управление.

Ответ на вопрос об эффективном распределении экономических ресурсов волнует исследователей социально-экономических процессов не одно столетие. Поиск «вечного двигателя» экономической системы, экономической и социальной справедливости часто завершался крахом утопии, либо фанатичности очередного описания реальности. Новые трактовки приобретает теория К. Маркса об отчужденном труде, конвертации капитала, рентных отношениях Д. Рикардо в контексте современного кризиса управления [1]. Система является неустойчивой, если не отвечает признакам целостности объектов ее составляющих [2]. Современная научная мысль определяет устойчивость системы как совокупность трех сфер: «экономической, соци- альной и экологической» [5].

Авторами предлагается ввести четвертый элемент устойчивого развития системы - «информация», активизирующий воспроизводство нематериального капитала в актуальной для системы форме. Воспроизводственный цикл определяется потребностью человека в развитии через непрерывное потребление новой информации. Исследовательский интерес представляет собой феномен, который может быть обозначен «ловушкой осведомленности», суть которого сводится к следующему: человек, вынужденный постоянно «потреблять» входящий поток информации все в большей степени утрачивает способность ее критически анализировать, структурировать и создавать новый интеллектуальный 
продукт. Действенным способом преодоления непрерывно повторяющихся информационных циклов оказался метод шокового эпатажа, когда вопреки ожиданиям потребители информационного продукта получают новую степень свободы конвертации информации и капитализации популярности, что сформировало новый рынок совершенной конкуренции в области продажи новых информационных шоков.

На основе манипуляции информационными шоками появляется ряд популярных сфер деятельности, не требующих связи с наследием предыдущих поколений, что усложняет механизм управления на основе ценностной структуры [4]. Перечисленное является предпосылками формирования систем непрерывного потребления. Парадоксально, что в противовес лимбической системе, информационная зависимость проявлена в большей степени в области потребления нематериальных, информационных продуктов. Противостояние «информационному потопу» может принимать формы: адаптации, игнорирования, либо принятия сильных сторон новой формирующейся информационной системы. Информационное пресыщение требует защиты капитала информации и знаний, меняет систему мотивации на рынке рабочей силы. Капитал приобретает новые формы конвертации: репутации, знаний, социальных связей. По данным ежегодного отчета независимого консультационного агентства Brand Finance стоимость нематериальных активов мира составляет в 2019 году 49,9 триллионов долларов США [8]. Вклад труда в выпускаемой продукции становится меньше, а интеллектуальная составляющая больше.

Кризис управления по-разному проявляется на различных рынках. Ярче всего иллюстрирует сложившуюся ситуацию рынок рабочей силы как индикатор развития человеческих способностей к труду, формирующих ценность, спрос и предложение на рынке. В рейтинге наиболее популярных профессий, пользующихся интересом среди молодого поколения, лидирует деятельность «блогеров». Наибольшее признание, а, следовательно, и материальное поощрение, получают блогеры изменяющие систему представлений о социально-экономическом устройстве, моральных, социальных, экономических ценностях производства и потребления благ и услуг, образе жизни и хозяйственной деятельности. Основной продукт блогера не является материальным, нацелен на формирование ценности потребителей. И здесь наблюдается хаотичность, так как эффективность деятельности блогера во многом определяется степенью ввода новых форм ценностей, преодоления границ, устоявшихся моральных, политических, социально-экономических норм системы, что усиливает ее нестабильность, энтропию.

В контексте проведенного исследования авторами предлагается трактовать коэффициент деградации нематериального капитала как отрицательную ренту от нематериального информационного капитала. В исследуемом случае информация не конвертируется в одну из форм капитала, а снижает степень управляемости региональной социально-экономической системой.

Рассмотрим альтернативный сценарий конвертации информации воспользовавшись коэффициентом преобразования. Структура регионального потенциала управления конкурентоспособностью региона, на основе коэффициента преобразования представлена в формуле 1.

$$
\text { К пр. = Пс. э./П рес. }
$$

где:

К пр. - коэффициент преобразования;

Пс. э. - достигнутый социально-экономический потенциал (нематериальный капитал);

Прес. - базовый ресурсный потенциал региона.

Формула 1 позволяет эффективно использовать материальные и нематериальные ресурсы региона, что особенно актуально в условиях нестабильности, кризиса социально-экономической системы.

В условиях нестабильности социально-экономических систем, в 2019 году практически перед всем человечеством возникла угроза Ковид-19, спровоцировавшего, либо экстраполировавшего уже сформированные предпосылки кризиса управления социально-экономическими системами. Региональная неоднородность в распределении ресурсов, устойчивости, информационной осведомленности оставляет регионам Российской Федерации временные лаги адаптации, позволяющие сформировать стратегию управления, основанную на внутренних pecypcax.

Управление системой, ориентированной, в первую очередь, на материальные, лимбические потребности, логично укладывается в име- 
ющиеся концепции управления большими группами, массовом мышлением и потреблением [3]. Однако, привычный уклад хозяйственной деятельности преобразовался с возможностями системы Интернет. Интернет способствовал формированию качественно новой системы удовлетворения потребностей человека, которые, наряду с материальными, актуализировали также интерес к самопознанию, что повлияло на парадигму управления, существенно увеличив издержки нерезонансного управления. Резонансное и превентивное управление социально-экономическими процессами в регионе определяется качеством преобразования нематериального капитала региона, определяет его эволюционную направленность, деградацию, энтропию [7].

Классифицируем ресурсы региона по информационному признаку актуализирующие «способности региона» и «возможности региона» в контексте наличия соответствующей материально-технической инфраструктуры и нематериального капитала. Выявим основные показатели классификационных групп, что позволит сформулировать компетенции способностей и возможностей региона. Таблица 1 иллюстрирует трактовку нематериального капитала как ресурса преобразования системы в направлении устойчивого развития за счет активизации эволюционного использования способностей и возможностей региональной социально-экономической системы с учетом инновационной активности региона, уровня занятых, имеющих высшее профессиональное образование, численности персонала сферы НИОКР.

Разработанная авторами классификация управления возможностями и способностями региона жизнеспособна при эффективном воспроизводстве нематериального капитала в регионе, резонансном методе управления социально-экономической системой. Информация - ресурс, не ограниченный в количественном измерении, но в качественном управленческом воздействии информация может служить как эволюционному преобразованию социально-экономической системы, так и деградации. Преобразование характеризуется неограниченностью сменой форм по эволюционной спирали, деградация же конечна, по закону энтропии. Следовательно, рекомендуется превентивно выявлять качественную определенность информационной среды системы, что, при организации качественного управления, будет способствовать устойчивому росту и развитию социально-экономических показателей региона.

Таким образом, проанализирована роль нематериального капитала в преобразовании региона. Выявлена конвертационная способность информации и потенциал ее управляющего воздействия на устойчивость социально-экономической системы, предложены пути нивелирования негативных последствий разнородности информации через превентивную систематизацию ее признаков, внедрение резонансных методов управления социально-экономической системой.

Таблица 1. Классификационная группа ресурсов преобразования нематериального капитала региона

\begin{tabular}{|c|c|c|}
\hline $\begin{array}{c}\text { Классификационная группа } \\
\text { ресурсов преобразования }\end{array}$ & $\begin{array}{c}\text { Показатели, определяющие ресурсы } \\
\text { группы }\end{array}$ & Способность/возможность \\
\hline «Способности» региона & $\begin{array}{l}\text { - уровень занятых, имеющих высшее } \\
\text { и среднее профессиональное образо- } \\
\text { вание; } \\
\text { численность персонала сферы НИОКР; }\end{array}$ & $\begin{array}{l}\text { - способность «Знание» } \\
\text { - способность «Компетенции» } \\
\text { - способность «Интеллектуальный } \\
\text { потенциал» }\end{array}$ \\
\hline «Возможности региона» & $\begin{array}{l}\text { - инновационная активность органи- } \\
\text { заций; }\end{array}$ & $\begin{array}{l}\text { - возможность «Конкурентное пре- } \\
\text { имущество» за счет использования } \\
\text { новых и высоких технологий; } \\
\text { - возможность «Потенциал развития» }\end{array}$ \\
\hline
\end{tabular}

Источник: составлено авторами по материалам исследования 


\section{Библиографический список}

1. Грудина С.И. Нелинейные методы исследования нематериального капитала регионов // Грудина С.И., Подгорная А.И. //«Казанский экономический вестник», № 4 (48) 2020., стр. 51-56

2. Грудина С.И. Теория развития энтропии региональных социально-экономических систем // «Казанский экономический вестник». 2021. № 3 (53) - С. 24-28.

3. Колесникова Ю.С., Фахрутдинова Е.В., Юрков Д.В. Привлечение и удержание высококвалифицированных специалистов в Республику Татарстан//Экономические науки, 2020, №12 (193), с. 246-250

4. М.Р. Сафиуллин, Л.А. Ельшин, Е.В. Фахрутдинова/Эффективность развития региональной высшей школы: качественно-количественный анализ (на примере Приволжского федерального округа)/Вестник высшей школы. - 2019. -№ 12. -с. 55-61.

5. Фахрутдинова Е.В., Камашева А.В., Валеев Э.Р. Статистический анализ дифференциации субъектов Российской Федерации по качеству жизни населения// Экономические науки. - 2019. -№ 12. - С. 356-362

6. Фахрутдинова Е.В., Грудина С.И. Индекс доверия как фактор устойчивости воспроизводства нематериального капитала региона/Е.В. Фахрутдинова, С.И. Грудина// Казанский экономический вестник. - 2021. № $5 .-$ C. 35-40.

7. Grudina S. Methodologikal aspects of investment risk management in the region/S. Grudina, A. Podgornaya // International Journal of Engineering Reseach and Technology ISSN: 0974-3154 Volume 13, Number 12 (2020), pp. 4417-4420

8. Global Intangible Finance Tracker (GIFT $\left.{ }^{\mathrm{TM}}\right) /$ an annual review of the world»s intangible value/November 2019/[Электронный ресурс https://brandfinance.com/wp-content/uploads/1/gift_2. pdf 